\title{
Permanent cardiac pacing using anterior pectoral veins
}

\author{
A G ARNOLD \\ From the Department of Cardiology, fohn Radcliffe Hospital, Headington, Oxford
}

SUMMARY We have used the anterior pectoral veins for inserting permanent transvenous cardiac pacemaker electrodes in 260 patients. Though this route is used in other centres it has not been published. We found it to be a reliable alternative to the more usual routes of pacemaker insertion, with a combined perforation and displacement rate of 9.6 per cent. We describe this technique of electrode insertion and compare the complication rates with those of other routes of implantation used in our department. All of the pacemaker implantations in this study were performed by doctors in the cardiology department, with no specialist surgical training.

The annual rate of new pacemaker implantations in Britain is still increasing, and the rate for 1980 has been predicted as 150 per million of the population. ${ }^{1}$ The majority of these pacemaker implantations use the transvenous route rather than an epicardial route. Though the external jugular vein and axillary vein ${ }^{2}$ are sometimes used for electrode insertion, the cephalic vein is the commonest transvenous route. ${ }^{1}$ Technical difficulties can arise with these routes, and in a variable proportion of patients the cephalic vein cannot be used. A more recent study described the use of direct subclavian vein puncture, but only in a group of 40 patients. $^{3}$

We describe a method which uses the anterior pectoral veins and compare our experience with this method with those other routes of electrode insertion.

\section{Subjects and methods}

We retrospectively analysed the records of all patients who had permanent cardiac pacemakers implanted between January 1975 and March 1979, regardless of the indication for pacing. The minimum period of follow-up was three months. Particular attention was paid to the complications of electrode displacement and myocardial perforation. In cases of repeated displacement each event was documented separately.

When the cephalic or subclavian routes were used the procedure was as previously described. ${ }^{3}$ If the anterior pectoral vein is used an incision is made midway between the axilla and the mid-point of Received for publication 22 August 1979 the clavicle (Fig. 1), of approximately $10 \mathrm{~cm}$ in length, after local anaesthetic infiltration. This incision is deep enough to expose the anterior surface of pectoralis major and crosses the line of cleavage between its sternal and clavicular heads. These two heads are separated by blunt dissection to

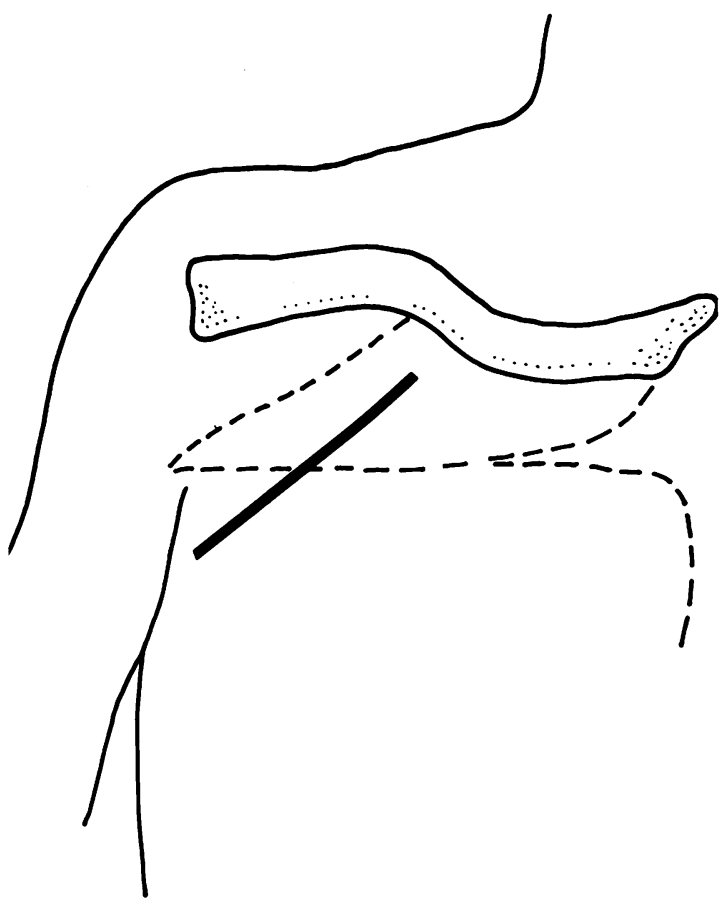

Fig. 1 Line of incision in relation to surface anatomy, and two heads of pectoralis muscle. 
expose an underlying layer of adipose tissue, crossed by the anterior pectoral veins in a neurovascular bundle. Separation of the muscle heads is eased by further local anaesthetic infiltration. A selfretaining retractor is then used to allow the vein to be dissected towards the subclavian vein, beneath the clavicular portion of pectoralis major, to a point where the calibre of the vein permits electrode insertion (Fig. 2). Underslung ties and an introducer make electrode insertion simpler, and the electrode then passes easily to the right atrium. The electrode is positioned in the right ventricle according to the radiological position of the electrode, the voltage threshold, and the intracardiac electrogram. When a stable position is found the electrode is first secured to the vein, and then to the surrounding fascia, by non-absorbable silk sutures. A subcutaneous pouch is fashioned superficial to pectoralis major to accommodate the generator unit.

Small surface area, non-wedged electrodes were used for subclavian vein insertion. With other routes of insertion large surface area and wedge electrodes were also used. There were two basic endocardial unipolar electrode types used in the study (Devices SC62 and LEM A7602), though some of the LEM electrodes differed in their tip dimensions (A7602B, A8603, and A8603B).

\section{Results}

The results of all three routes of transvenous pacemaker insertion are listed (Table). Electrode displacement and myocardial perforation are grouped together because of the difficulty occasionally in differentiating between these two complications.

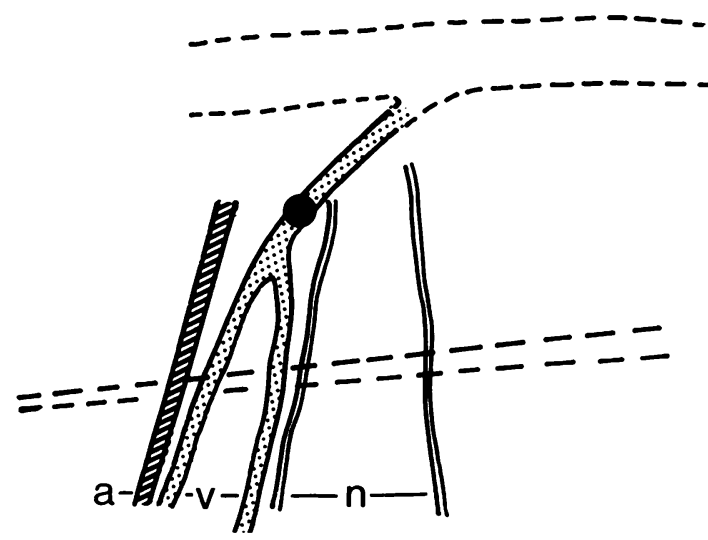

Fig. 2 Neurovascular bundle beneath pectoralis major. The large dot indicates the point of electrode insertion. $a$, artery (thoracic branch of thoraco-acromial artery); $v$, vein (anterior pectoral vein); $n$, nerve (medial and lateral branches of the pectoral nerve).
Table Complications of transvenous pacemaker insertion

\begin{tabular}{|c|c|c|c|c|}
\hline & \multicolumn{4}{|c|}{ Route of insertion } \\
\hline & $\begin{array}{l}\text { Anterior } \\
\text { pectoral } \\
\text { vein }\end{array}$ & $\begin{array}{l}\text { Subclavian } \\
\text { vein }\end{array}$ & $\begin{array}{l}\text { Cephalic } \\
\text { vein }\end{array}$ & Total \\
\hline \multirow{3}{*}{$\begin{array}{l}\text { Uncomplicated cases } \\
\text { Displacement and } \\
\text { perforation (No.) } \\
\text { Displacement and } \\
\text { perforation (\%) } \\
\text { Total }\end{array}$} & 235 & 61 & 151 & 447 \\
\hline & 25 & 16 & 23 & 64 \\
\hline & $\begin{array}{c}9 \cdot 6 \\
260\end{array}$ & $\begin{array}{l}20 \cdot 78 \\
77\end{array}$ & $\begin{array}{l}13 \cdot 22 \\
174\end{array}$ & $\begin{array}{l}12 \cdot 5 \\
511\end{array}$ \\
\hline \multirow[t]{2}{*}{ p } & 0.02 & & & \\
\hline & & NS & & \\
\hline
\end{tabular}

Other complications such as a rise in threshold, infection, and electrode fracture occurred in eight per cent of our whole group, but were evenly distributed between the three routes of insertion. In addition, axillary vein thrombosis occurred in three patients, all in the cephalic vein group. One patient sustained a large pneumothorax as a result of use of the subclavian vein route. These complications did not follow use of the anterior pectoral vein.

Although insertion of an electrode via the anterior pectoral vein meant that the electrode was placed through the muscle layer, neither impaired motor activity nor discomfort were noted.

The results of pacemaker electrode insertion were analysed by the $x^{2}$ test with Yates's correction.

\section{Discussion}

The commonest complication of permanent cardiac pacemaker insertion is electrode displacement, and this usually occurs in the first 48 hours after insertion $^{4}$ and occasionally up to three months afterwards. ${ }^{5}$ Several series have shown displacement rates of 0 to 40 per cent, ${ }^{6-8}$ but the average rate in this country is 10 per cent. ${ }^{1}$ There are two main reasons why electrodes displace, the first being the amount of slack left in the atrium, which can be too much or too little; the second is traction on the proximal portion of the electrode. ${ }^{4}$

Pacemaker electrode perforation of the right ventricle can be fatal ${ }^{9}$ because of tamponade, but more often presents as pacemaker malfunctioning, and requires a further operation for repositioning. ${ }^{10-12}$ The documented rate of perforation has varied between 2 and 7 per cent in several series. $^{51213}$ Though physical examination and chest radiographs are of little help in diagnosing this, the intracardiac electrogram can be of assistance. ${ }^{9}$ In practice, when faced with pacemaker malfunction, it may be difficult to differentiate between 
electrode perforation and displacement. In either case the electrode must be repositioned or replaced, and this difficulty might account for the varying perforation rates that have been reported.

If the point of electrode insertion into the vein is too close to the shoulder joint skeletal movement may cause traction on the electrode, and predispose to displacement. This may be the reason why cephalic vein insertion was less successful than anterior pectoral vein pacing in our study, and might account for the relatively high displacement rate when the axillary vein was used. ${ }^{2}$ The cephalic vein cannot be used in 5 to 20 per cent of patients because of venospasm or anatomical variations. ${ }^{513}$

If the subclavian puncture method is used many additional complications may be encountered, such as pneumothorax, ${ }^{14}$ arteriovenous fistula, ${ }^{15}$ air embolism, ${ }^{16}$ and phrenic nerve damage, ${ }^{17}$ though they are likely to be rare if the subclavicular approach is used. Pneumothorax occurred as a complication in one of our cases of subclavian puncture. Our complication rate was higher than the earlier study, ${ }^{3}$ but the rate was artificially low in that study since the number of patients with displacement, not the total number of displacement events, was recorded. We suspect that our complication rate was higher with this route because the electrode cannot be secured directly to the vein, but only to the fascia. This could make the electrode more prone to traction. With the subclavian route of insertion it can be difficult to insert large or wedgetipped electrodes because of insufficient space between the clavicle and the first rib. ${ }^{3}$

The anterior pectoral vein route involves more dissection than alternative routes and tends to be a longer procedure. Separation of the muscle bellies can be uncomfortable unless adequate local anaesthesia is used. Occasionally the anterior pectoral veins are too small to be used, and alternatives have to be sought. Similarly, the cephalic and subclavian routes cannot always be used. This might be because the vein cannot be located, or because an electrode will not pass along the vein easily, though the vein can be entered. In this situation it is helpful to be able to use alternative routes, and we have found the anterior pectoral vein of value. Our complication rate was the lowest in the anterior pectoral vein group, and the difference between the complication rate in this group and the subclavian group satisfied standard tests of statistical significance.

In our total group of patients two main types of electrode were used, with similar complication rates for each. A further type of electrode was withdrawn from use because of an unacceptably high complication rate, and was therefore excluded from our study. Only experienced operators were used since the experience of the operator can obviously influence the rate of displacement. ${ }^{18}$ Similarly, increasing experience of a particular transvenous route improves the results, and our own results seem to support this.

In this study we describe the use of the anterior pectoral vein as a route for the insertion of permanent pacemaker electrodes. Our results suggest that this is a safe method which appears to be at least as effective as other routes previously described.

I am grateful to Mr H F M Bassett of Manchester Royal Infirmary for permission to report a technique that he first devised and to Professor P Sleight for his helpful advice.

\section{References}

${ }^{1}$ Sowton E. Use of cardiac pacemakers in Britain. Br Med F 1976; 2: 1182-4.

'Orr JD, McNeill GP. Permanent cardiac pacing through the axillary vein. $\mathcal{F} R$ Coll Surg Edinb 1979; 24: 91-3.

${ }^{3} \mathrm{McNeill}$ GP, Taylor NC. Use of subclavian vein for permanent cardiac pacing. Br Heart $\mathcal{F} 1978$; 40: 114-6. ${ }^{4}$ Bluestone R, Davies G, Harris A, Leatham A, Siddons $\mathrm{H}$. Long-term endocardial pacing for heart-block. Lancet 1965; 2: 307-12.

${ }^{5}$ Grendahl H, Sivertssen E. Pacemaker wires and electrodes. A follow-up study. Acta Med Scand [Suppl] 1976; No. 596: 12-21.

${ }^{6}$ Parsonnet V. A decade of permanent pacing of the heart. Cardiovascular clinics. Philadelphia: FA Davis, 1970: 2: 181-99.

${ }^{7}$ Bette L, Doenecke P, Rettig G. Results of permanent cardiac stimulation therapy. In: Schaldach M, Furman S, eds. Advances in pacemaker technology. New York: Springer-Verlag, 1975: 75-90.

${ }^{8}$ Fiandra O, Espasandin W, Barbieri FF, et al. Selfanchoring electrode for implantable pacemakers. $\mathrm{Am}$ Heart f 1976; 91: 468-74.

${ }^{9}$ Vera Z, Mason DT, Awan NA, et al. Cardiac perforation by endocardial pacemaker electrodes (abstract). Clin Res 1976; 24: 244A.

${ }^{10}$ Edhag O. Long term cardiac pacing. Acta Med Scand [Suppl] 1969; No. 502: 9-110.

${ }^{11}$ Bernstein V, Rotem CE, Pertz DI. Permanent pacemakers: 8 year follow up study. Ann Intern Med 1971; 74: 361-9.

${ }^{12}$ Rubenfire M, Anbe DT, Drake EH, Ormond RS. Clinical evaluation of myocardial perforation as a complication of permanent transvenous pacemakers. Chest 1973; 63: 185-8.

${ }^{13} \mathrm{Ohm}$ O, Segadal L, Skagen DW. Complications with permanent endocardial electrode systems. Acta Med Scand [Suppl] 1976; No. 596: 22-9.

${ }^{14}$ Walker MM, Sanders RC. Pneumothorax following supraclavicular subclavian venepuncture. Anaesthesia 1969; 24: 453-60. 
${ }^{15}$ Farhat $\mathrm{K}$, Nakhjavan FK, Cope C, et al. Iatrogenic arteriovenous fistula: a complication of percutaneous subclavian vein puncture. Chest 1975; 67: 480-2.

${ }^{16}$ Yoffa $D$. Supraclavicular subclavian venepuncture and catheterisation. Lancet 1965; 2: 614-7.

${ }^{17}$ Epstein EJ, Quereshi MSA, Wright JS. Diaphragmatic paralysis after supraclavicular puncture of subclavian vein. $\mathrm{Br}$ Med $\mathcal{f}$ 1976; 1: 693-4.
${ }^{18}$ Charles RG, Clarke LM, Drysdale M, Sequeira RF. Endocardial pacing electrode design and rate of displacement. Br Heart $\mathcal{F} 1977$; 39: 515-6.

Requests for reprints to Dr A G Arnold, Department of Cardiology, John Radcliffe Hospital, Headington, Oxford OX3 9DU. 